\title{
Competições em ciência usando tecnologia: um caso de estudo do comportamento das escolas participantes em Portugal
}

\section{Science competitions using technology: a study of the behavior of the participating schools in the CNC in Portugal}

\author{
Alberto Oliveira da Silva ${ }^{1}$ \\ https:/ / orcid.org/0000-0002-3496-6802 \\ Adelaide Freitas ${ }^{1}$ \\ https:// orcid.org/0000-0002-4685-1615 \\ Maria Paula de Sousa Oliveira ${ }^{1}$ \\ https:// orcid.org/0000-0002-6376-1099 \\ Alexandre Mota da Silva ${ }^{1}$ \\ https:/ / orcid.org/0000-0002-5693-5775
}

\begin{abstract}
Resumo: Neste trabalho investiga-se a dinâmica de escolas do $3^{\circ}$ ciclo do Ensino Básico em Portugal, na preparação e participação em uma competição desenvolvida em ambiente computacional sobre conteúdos curriculares de Matemática, Português, Físico-Química e Geologia. Foi realizada uma análise fatorial exploratória de dados empíricos relativos às 143 escolas participantes nas competições realizadas em 2015, analisando-se as suas caraterísticas de atuação. Foram identificados quatro fatores latentes descrevendo o comportamento das escolas: Treino quantitativo, Treino qualitativo, Prestação e Utilizadores, constatando-se que: (i) a participação na competição de Matemática é predominante; (ii) escolas participantes em duas ou três competições apresentam diferentes dinâmicas de preparação; (iii) escolas que participam apenas em Matemática e Físico-Química parecem adotar estratégias pedagógicas mais articuladas e eficientes. Reconhece-se que, embora as escolas participantes desenvolvam trabalhos de preparação, existe uma tendência para as escolas apresentarem estratégias distintas de atuação consoante a combinação de grupos disciplinares presentes nas competições oficiais.
\end{abstract}

Palavras-chave: Competições em ciência. Escolas. Ensino básico. Portugal.

\begin{abstract}
In this work we investigate the dynamics of 143 schools of the 3rd cycle of Basic Education in Portugal, regarding the preparation and participation in online science competitions on curricular contents of Mathematics, Portuguese, Physics and Chemistry and Geology. An exploratory factorial analysis of empirical data concerning the competitions in 2015 was carried out, to analyze the characteristics inherent to schools' performance. Four latent factors describing the schools' behavior were identified: Quantitative Training, Qualitative Training, Proficiency and Users, which allowed us to verify that: (i) participation in mathematics competition is predominant; (ii) schools participating in two or three competitions present different preparation dynamics; (iii) schools involved only in Mathematics and Physics and Chemistry competitions seem to adopt a more articulated and efficient pedagogical strategy. Although all schools develop a preparatory work before competitions, the strategies used seem to be related to the combination of distinct disciplinary groups participating in the competitions.
\end{abstract}

Keywords: Science competitions. Schools. Basic education. Portugal.

\footnotetext{
${ }^{1}$ Universidade de Aveiro, Departamento de Matemática, Aveiro, Portugal. E-mail: <albertos@ua.pt>.
} 


\section{Introdução}

Nas últimas décadas, a utilização das tecnologias de informação e da comunicação no processo educativo deixou de ser uma novidade para se tornar uma realidade (REZENDE, 2002). Em Portugal, foram promovidas diversas iniciativas para o desenvolvimento e implementação tecnológica na educação escolar, como o projeto MINERVA (Meios Informáticos no Ensino: Racionalização, Valorização, Atualização), entre 1985 e 1994, o projeto Nónio Século XXI, entre 1996 e 2002, e a estrutura de coordenação do Programa Internet na Escola, uARTE (Unidade de Apoio à Rede Telemática Educativa), entre 1997 e 2003 (SAMPAIO; COUTINHO, 2012).

Nesse sentido, em 1989, foi concebido na Universidade de Aveiro o Projeto Matemática Ensino (PmatE) ${ }^{2}$, cujo objetivo era a aplicação das tecnologias da comunicação e informação na promoção da aprendizagem da Matemática (ANJO; OLIVEIRA, 2010), tendo desenvolvido, na sua génese, a competição EQUAmat com conteúdos de Matemática para o $3^{\circ}$ ciclo do Ensino Básico $\left(7^{\circ}, 8^{\circ}\right.$ e $9^{\circ}$ anos de escolaridade). Atualmente, o PmatE desenvolve conteúdos digitais parametrizados para várias áreas científicas e níveis de ensino (básico, secundário e universitário), que são disponibilizados por uma Plataforma de Ensino Assistido por computador (PEA) (ver, por exemplo, PEIXOTO et al., 2012), e realiza, anualmente, no terceiro trimestre letivo, as Competições Nacionais de Ciência (CNC), um evento de abrangência nacional em Portugal, que decorre na Universidade de Aveiro e tem por base os conteúdos desenvolvidos sobre tópicos curriculares do ensino português.

A PEA permite que os alunos registrados treinem online para as competições, realizando provas que abrangem todo o conteúdo curricular da formação dos alunos e que são testados nas competições presenciais. No ambiente de competição, as provas são organizadas por níveis, sendo que cada nível utiliza um mesmo modelo gerador de questões (MGQ) e tal que, duas provas a correr simultaneamente em dois computadores são distintas, mas formalmente equivalentes no sentido que mantêm o mesmo nível de dificuldade e o mesmo objetivo didático e pedagógico. No modo competição são atribuídos pontos pelo número de níveis completados corretamente e pelo tempo gasto na competição.

Em algumas provas das CNC, nomeadamente na EQUAmat, a existência de "vidas" torna a competição mais próxima dos jogos digitais. Dentro desse contexto, é possível se dizer que as CNC fazem uso de caraterísticas da gamificação (SIMÕES; REDONDO; FERNÁNDEZ, 2013), uma vez que a geração aleatória de questões por intermédio dos MGQ é um instrumento estratégico na manutenção do nível de interesse e motivação dos estudantes na busca do conhecimento científico, tirando proveito da combinação do saber e da tecnologia com a competição.

Em 2015, ano em que incide a presente investigação, as CNC constaram de quatro competições oficiais destinadas ao $3^{\circ}$ ciclo do Ensino Básico em Portugal, nomeadamente, EQUAmat, Dar@língua, Geo@NET e FisQ, que correspondem às disciplinas curriculares de Matemática (M), Português (L), Ciências Naturais (envolvendo apenas conteúdos de Geologia)

${ }^{2}$ Disponível em: <https://pmate.ua.pt/oficial/>. Acesso em: 16 ago. 2018. 
(G) e Ciências Físico-Químicas (F), respetivamente. Este estudo faz uma abordagem quantitativa, numa perspetiva investigativa, do trabalho de preparação desenvolvido por 143 escolas do $3^{\circ}$ ciclo do Ensino Básico, que participaram em pelo menos uma daquelas quatro competições e tem como objetivo identificar os fatores latentes que emergem das escolas participantes face à combinação da utilização de tecnologia na educação escolar e da competição em ambientes computacionais.

\section{Enquadramento do estudo}

É sabido que o raciocínio abstrato, o domínio matemático e a linguagem específica das ciências são fatores caraterísticos que dificultam o aprendizado (BLACK; ATKIN, 1996; FOUREZ, 2003). De acordo com Miranda (2007), o emprego da tecnologia em adição às práticas comumente verificadas em salas de aula é um expediente cada vez mais utilizado por educadores como recurso de aprendizagem, embora a disponibilização dessas tecnologias computacionais, por si só, não seja capaz de gerar uma melhoria na assimilação do conhecimento transmitido.

No que diz respeito à introdução de novas tecnologias em sala de aula, o ganho real na aquisição de conhecimento por parte dos alunos só ocorre quando os professores se comprometem em adquirir as competências tecnológicas necessárias, assim como acreditam nas possibilidades proporcionadas pela tecnologia da informação e da comunicação. Além disso, também é necessário que educadores sejam capazes de desenvolver atividades que instiguem a curiosidade e a imaginação dos alunos. A competição, sendo uma atividade bem estruturada e com objetivos concretos, pode ser encarada como um fator de motivação e entusiasmo para os estudantes (CHENG et al., 2009). O conceito de aprendizado como processo reconstrutivo adquire importância central nesse contexto, significando que os alunos irão agir como protagonistas na construção dos novos conhecimentos, fundados em informações já assimiladas anteriormente (MIRANDA, 2007).

A ênfase nos processos sócio-históricos desenvolvida por Vygotsky (1991) conduz à ideia de que os indivíduos envolvidos no processo de aprendizagem estabelecem relações de dependência mútua. Na determinação do processo constituído pelo par ensino-aprendizagem, existem sempre três figuras: quem aprende, quem ensina, e a relação construída entre estes (OLIVEIRA, 2010). Desse cenário, resulta que o processo de desenvolvimento individual só pode ocorrer diante de situações propícias, o que levou Vygotsky a elaborar o conceito de Zona de Desenvolvimento Proximal (ZDP).

Segundo Rego (2000), a ZDP idealizada por Vygotsky pode ser resumida como a distância entre os níveis de desenvolvimento real e potencial do educando. Tal distância pode ser entendida como o intervalo existente entre aquilo que o aluno é capaz de realizar de forma autónoma e aquilo que ele faz com o auxílio dos outros participantes do grupo social. O progresso do estudante é entendido como algo latente e que irá aflorar em algum momento no futuro.

Vygotsky (1991) sugere que uma das maneiras para se formar uma ZDP no educando é através do jogo, já que este, segundo Negrine (1995, p. 16), “[...] leva a criança a estar sempre acima de sua idade média, isto é, acima de sua conduta diária, uma vez que o jogo contém todas as tendências evolutivas de forma condensada, sendo, em si mesmo, uma considerável fonte de desenvolvimento". 
Sob um outro ponto de vista, Coutinho e Lisbôa (2011, p. 12) assinalam que a tradução da utilização da Internet e tecnologias digitais em progresso escolar numa era de primazia dos sistemas de informação, quando o "antigo modelo hierárquico de concepção e transmissão do conhecimento vem sendo substituído pela horizontalidade, e no qual todos são agentes no sistema de autoformação", requer a presença de alguns elementos fundamentais desencadeadores do processo de aprendizado, tais como o desafio e o contexto relacional, definidos como sendo as "[...] situações até então não vivenciadas pelo aprendente e que vai impulsioná-lo a buscar formas diferenciadas de conceber e construir o conhecimento" e o "[...] ambiente de expressão, partilha e, simultaneamente, de testagem de novas formas de ação e intervenção social” (COUTINHO; LISBÔA, 2011, p. 12). Nessa perspetiva, o jogo e a competição desempenham um papel fundamental no aprendizado. Segundo Silva e Kodama (2004, p. 3),

[...] a teoria de Piaget mostra que a competição nos jogos é parte de um desenvolvimento maior, que vai do egocentrismo a uma habilidade cada vez maior em descentrar e coordenar pontos de vista. Este processo de desenvolvimento pode ser visto não somente nos jogos, mas também no julgamento moral, na linguagem, na classificação, na conservação, na construção de uma estrutura espaço-temporal e na causalidade.

Ainda segundo aquelas autoras, os jogos propiciam aos alunos a oportunidade de adquirir autoconfiança, senso crítico e organizacional e a possibilidade de desenvolver seu raciocínio, pois “[...] os jogos são instrumentos para exercitar e estimular um agir-pensar com lógica e critério, condições para jogar bem e ter um bom desempenho escolar" (SILVA; KODAMA, 2004, p. 3). Por outro lado, e não menos importante, o seu envolvimento em competições fora do ambiente escolar e que premiam o desempenho, tende a propiciar futuramente, como adulto, realizações profissionais e criativas de elevado sucesso, como referem Worrell el al. (2016).

As competições em ciência promovidas pelo PmatE têm a dinâmica de um jogo que, em contexto educativo e integradas no plano anual de atividades de uma escola, podem motivar os agentes educativos (alunos e professores) a desenvolver atividades educativas diferentes das usuais, que comprometem os alunos com o processo de aquisição de conhecimento, desencadeando a formação da ZDP considerada em Vygotsky (1991). Em consonância com a importância da combinação do jogo como ferramenta de desenvolvimento pessoal do aluno e da implementação das tecnologias da informação e da comunicação no ambiente de aprendizagem, o PmatE foi concebido para proporcionar mecanismos estimulantes à aprendizagem visando o aumento do interesse e melhoria do desempenho dos estudantes do ensino fundamental e médio de Matemática (PAIS; CABRITA; ANJO, 2014), tendo sido posteriormente estendido a outras áreas disciplinares.

\section{Objetivo}

O presente estudo pretende compreender o processo de utilização da ferramenta computacional PEA pelas escolas (alunos e professores) que participam nas $\mathrm{CNC}$ e que, ao final, irá resultar em determinado nível de desempenho nas competições. Concretamente, explora a 
existência de traços/comportamentos relevantes das escolas face à utilização da PEA quando perante a possibilidade de participar em quatro competições em Ciências a nível nacional. As seguintes questões de investigação foram consideradas para visar o propósito do presente estudo:

1) Quais as caraterísticas que emergem da participação das escolas nas CNC?

2) Existem grupos disciplinares que evidenciam um desempenho diferenciado das escolas nas CNC?

\section{Métodos e procedimentos}

\section{Opções metodológicas}

A PEA desenvolvida pelo PmatE, além de ser o portal de acesso para treinos e para as competições, permite recolher um vasto conjunto de dados sobre a sua utilização por parte de distintos agentes educadores. Assim, partindo-se de várias variáveis quantitativas registradas na plataforma, foram examinadas e exploradas as relações existentes entre elas, utilizando-se a análise fatorial exploratória. Baseando-se na suposição de que a realidade pode ser mensurável, optou-se por uma investigação quantitativa exploratória. Ao descrever/identificar fatores subjacentes aos dados, é possível perceber uma componente descritiva, motivo pelo qual o tipo de pesquisa aqui considerada é ainda de natureza descritiva.

\section{Participantes}

O estudo adota, como sujeitos de pesquisa, as 143 escolas participantes na fase presencial das CNC que ocorreram em maio de 2015. Uma vez que os dados em análise correspondem a 100\% das escolas participantes (143) nas CNC2015, para este trabalho não se recorreram a processos de seleção de amostras (HILL; HILL, 2008). Embora as CNC se realizem há mais de uma década no formato atual, a fim de acautelar a máxima credibilidade na investigação, optou-se por integrar no estudo apenas a informação recolhida em um único ano, fazendo com que as reformas educativas curriculares aplicadas ao longo de um mesmo período alcançassem todos os participantes e garantissem a maior uniformidade possível do percurso curricular a todos os alunos envolvidos. Assim, foi escolhido o ano de 2015, último ano em que se garante tal critério de opção. Naquele ano foram realizadas quatro competições envolvendo um total de 3531 alunos; a quase totalidade das instituições (140 escolas) optou por participar na competição de Matemática (EQUAmat), 28 na competição de Português (Dar@língua), 21 na competição de Geologia (Geo@NET) e 22 na competição de Ciências Físico-Químicas (FisQ), havendo escolas que combinaram a sua atuação com uma ou mais participações, conforme retrata a Tabela 1. Os distritos mais representados, com 60,8\% das escolas intervenientes nas CNC2015, são Aveiro, Porto e Coimbra, justificando-se tal representatividade pela proximidade geográfica do local do evento. Os distritos mais afastados, contudo, fizeram-se representar de forma considerável, computando 32,2\% das escolas participantes nas CNC2015. Das 6 escolas que participaram nas quatro competições, 3 são do distrito de Aveiro, representando 2,1\% do total de escolas que fizeram parte do evento. Embora 143 escolas tenham marcado presença nas competições (note-se que os custos financeiros com o deslocamento são suportados por 
cada escola), um total de 266 escolas de todo o país esteve envolvido na edição de 2015 das CNC. Esta diferença de 123 escolas, envolvidas, mas não participantes nas CNC2015, sugere o efetivo recurso à utilização da PEA para fomentar o ensino e a aprendizagem de diversos conteúdos curriculares nas diversas escolas do território português.

\section{Variáveis}

Como técnica de coleta de dados, optou-se pela observação quantitativa, utilizando a PEA como instrumento técnico específico na obtenção automática de dados quantitativos. Os dados coletados são relativos a doze parâmetros previamente definidos e que estão relacionados com a utilização da PEA por escola, sendo que oito deles são extraídos quatro vezes, um por cada competição. Concretamente, os dados em análise correspondem aos indicadores de atividade das escolas, quer em períodos temporais distintos antecedentes às competições (uma e três semanas antes das competições), quer durante a competição. De forma a obter informação resumida e estruturada de tais indicadores, privilegiou-se o cálculo de medidas estatísticas sumárias por escola e competição (nomeadamente, com o cálculo de frequências absolutas, médias e proporções) como instrumento aplicável na coleta de dados para a investigação (COHEN; MANION; MORRISON, 2000).

Tabela 1. Diferentes combinações de participação das escolas nas CNC2015

\begin{tabular}{|c|c|c|c|c|c|}
\hline $\begin{array}{l}\text { Conjunto de } \\
\text { competições }\end{array}$ & $\begin{array}{l}\text { EQUAmat } \\
(\mathrm{n}=140)\end{array}$ & $\begin{array}{c}\text { Dar@língua } \\
(\mathrm{n}=28)\end{array}$ & $\begin{array}{c}\text { Geo@NET } \\
(\mathrm{n}=21)\end{array}$ & $\begin{array}{c}\text { Fis } Q \\
(\mathrm{n}=22)\end{array}$ & $\begin{array}{l}\text { Escolas } \\
(\mathrm{n}=143)\end{array}$ \\
\hline M & $\sqrt{ }$ & & & & 98 \\
\hline $\mathrm{L}$ & & $\sqrt{ }$ & & & 1 \\
\hline G & & & $\sqrt{ }$ & & 1 \\
\hline $\mathrm{F}$ & & & & $\sqrt{ }$ & 1 \\
\hline ML & $\sqrt{ }$ & $\sqrt{ }$ & & & 12 \\
\hline $\mathrm{MG}$ & $\sqrt{ }$ & & $\sqrt{ }$ & & 7 \\
\hline MF & $\sqrt{ }$ & & & $\sqrt{ }$ & 3 \\
\hline MLG & $\sqrt{ }$ & $\sqrt{ }$ & $\sqrt{ }$ & & 2 \\
\hline MLF & $\sqrt{ }$ & $\sqrt{ }$ & & $\sqrt{ }$ & 7 \\
\hline MGF & $\sqrt{ }$ & & $\sqrt{ }$ & $\sqrt{ }$ & 5 \\
\hline MLGF & $\sqrt{ }$ & $\sqrt{ }$ & $\sqrt{ }$ & $\sqrt{ }$ & 6 \\
\hline
\end{tabular}

M: Matemática. L: Português. G: Geologia. F: Físico-Química.

Fonte: elaborada pelos autores.

As doze caraterísticas medidas por escola foram sumariamente descritas no Quadro 1 e constituem a base primária dos dados recolhidos para o estudo. Como já referido, oito dessas 
doze caraterísticas foram registradas sobre cada uma das quatro competições; assim, na notação de cada uma, foi introduzido o índice $j$, indicativo da competição a que se refere: EQUAmat corresponde $j=1$, Dar@língua o índice $j=2$, Geo@NET o índice $j=3$ e, finalmente, à competição FisQ corresponde $j=4$. Para a determinação do desempenho global de cada escola para cada competição recorreu-se à fórmula usada pelo $\mathrm{PmatE}^{3}$ para definir a escola vencedora em cada competição nas CNC2015. A fórmula converte em pontos os resultados das equipes de determinada escola participante. Quanto mais pontos conquistados, melhor o desempenho da escola por competição. Uma vez que o número máximo possível de pontos varia por competição $($ EQUAmat=360000, Dar@língua =180000, Geo@NET = FisQ=270000), o desempenho de uma escola numa competição (variável dj no Quadro 1) foi ajustado para uma mesma escala nas quatro competições, passando a ser definido pelo quociente entre a pontuação obtida pela escola em uma competição e a pontuação máxima possível que poderia ser alcançada nessa competição. Convém referir que a escolha dos períodos uma e três semanas antes da competição oficial se deve ao fato de a seleção dos alunos participantes ser da responsabilidade da escola e a inscrição definitiva das equipes que virão disputar a CNC ser realizada na semana anterior. Salienta-se ainda a utilização das variáveis tempos médios, $u 1, u 3$ de consulta da PEA e $t 1 j$, t3j de treinos, como indicadores na presente análise, à semelhança do que foi feito por Cagiltay, Ozcelik e Ozcelik, (2015), que utilizaram o tempo gasto na leitura das questões e das respetivas respostas como medidas de avaliação na implementação de uma competição.

Quadro 1. Variáveis analisadas por escola e extraídas da PEA nas 4 competições $(j=1,2,3,4)$ relativas à edição CNC2015

\begin{tabular}{|c|l|}
\hline Variável & \multicolumn{2}{|c|}{ Descrição } \\
\hline Utilizadores em números \\
\hline$a$ & alunos registrados na PEA \\
\hline$p$ & professores registrados e que acederam a PEA em 2015 \\
\hline$e j$ & equipes participantes na competição $j$ \\
\hline Utilização da PE $A$ \\
\hline$u 1, u 3$ & $\begin{array}{l}\text { Tempos médios (em segundos) de utilização diária da plataforma para consulta de } \\
\text { resultados e ranking dos alunos, discussão das respostas dadas, uma e três semanas antes } \\
\text { do evento, respetivamente. Estes tempos não contemplam os tempos de treino. }\end{array}$ \\
\hline$a 1 j, a 3 j$ & $\begin{array}{l}\text { Número de alunos que acedem aos treinos da competição } j \text {, uma e três semanas antes do } \\
\text { evento, respetivamente. }\end{array}$ \\
\hline$r 1 j, r 3 j$ & $\begin{array}{l}\text { Número de treinos realizados na competição } j \text {, uma e três semanas antes do evento, } \\
\text { respetivamente. }\end{array}$ \\
\hline$t 1 j, t 3 j$ & $\begin{array}{l}\text { Tempo médio (em segundos) de utilização diária da plataforma pelos alunos da escola em } \\
\text { treinos para a competição } j \text {, uma e três semanas antes do evento, respetivamente. }\end{array}$ \\
\hline Desempenho por competição \\
\hline \multicolumn{2}{|c|}{ pes } \\
\hline \multirow{2}{|c|}{ Desempenho da escola na competição $j$} \\
\hline
\end{tabular}

Fonte: elaborado pelos autores.

${ }^{3}$ Disponível em: <http://PmatE4.ua.pt/cnc/index.php/como-participar/regulamento>. Acesso em: 16 ago. 2018. 


\section{Tratamento dos dados}

Dado que se pretende uma análise na perspetiva global do evento CNC, foi realizada, por escola, uma agregação da informação relativa às quatro competições. Para tal, foi condensada cada uma das caraterísticas descritas no Quadro 1 em uma única variável normalizada. Concretamente, uma vez que as escolas participaram em quantidades diversas de competições (entre um e quatro), a agregação de cada caraterística foi feita pela adição dos valores atribuídos da caraterística nas competições em que participaram nas CNC e, em seguida, normalizou-se essa soma de forma proporcional ao número de competições em que a escola participou nas CNC. Neste sentido, considerou-se um fator $f$, definido pelo quociente entre o número de competições em que a escola participou e 4, que é o total de competições existentes $(f$ pode tomar o valor 1 , caso a escola participe em todas as competições; será igual a 0.75 , caso participe em três competições; 0.5 se participar em duas e 0.25 se fizer parte de apenas uma competição). Esta forma de agregação da informação corresponde a estimar o valor global da caraterística pelo seu valor médio no conjunto das competições em que a escola participou, o que significa admitir um comportamento uniforme da caraterística pelas quatro competições. As fórmulas usadas na agregação de cada caraterística registrada nas quatro competições encontram-se descritas na Tabela 2. Os dados relativos às variáveis $a, p, u 1$ e $u 3$ (Quadro 1) não foram submetidos a nenhum processo de adição, pois correspondem a medições obtidas por escola e não se referem a nenhuma competição específica. Os dados relativos a cada uma das restantes oito caraterísticas, exceto o desempenho da escola (dj no Quadro 1), foram adicionados sobre o conjunto das quatro competições. Em relação à variável $d j$, uma vez que nem todas as escolas participaram com 15 equipes, que é o número máximo permitido por competição, a agregação foi realizada calculando-se a média ponderada do desempenho das escolas nas quatro competições, sendo que os pesos foram definidos pela divisão do número de equipes participantes por competição pelo número total de equipes (por escola). Por fim, exceto em relação às variáveis $a, p$ e $e$ da Tabela 2, a adição dos valores observados nas quatro competições por caraterística foi normalizada, procedendo-se à sua multiplicação pelo fator $f$, resultando no valor médio estimado por caraterística. As variáveis $a, p$ e $e$ não foram afetadas pela fração $f$ por representarem o número total de elementos (alunos, professores e equipes, respetivamente) envolvidos nas CNC2015. É importante salientar que a aplicação do fator $f$ na obtenção do valor agregado de uma mesma caraterística privilegia as escolas que participaram em mais competições, uma vez que foi admitido que a propensão das escolas participarem nas quatro competições é a mesma (distribuição uniforme). Na realidade, com a introdução do fator $f$, será naturalmente esperado que as escolas com participação em menor número de competições nas $\mathrm{CNC}$ apresentem valores mais baixos nas suas estimativas agregadas, tornando-se inadequado comparar resultados agregados entre grupos de escolas que tenham participado em um número diferente de competições. 
Tabela 2. Ilustração de valores originais e valores agregados

\begin{tabular}{cl}
\hline Variável & \multicolumn{1}{c}{ Variável agregada (fórmula) } \\
\hline$a$ & $A=a$ \\
$p$ & $P=p$ \\
$e j$ & $E=e 1+e 2+e 3+e 4$ \\
$u 1$ & $U 1=u 1 \times f$ \\
$u 3$ & $U 3=u 3 \times f$ \\
$a 1 j$ & $A 1=(a 11+a 12+a 13+a 14) \times f$ \\
$r 1 j$ & $R 1=(r 11+r 12+r 13+r 14) \times f$ \\
$t 1 j$ & $T 1=(t 11+t 12+t 13+t 14) \times f$ \\
$a 3 j$ & $A 3=(a 31+a 32+a 33+a 34) \times f$ \\
$r 3 j$ & $R 3=(r 31+r 32+r 33+r 34) \times f$ \\
$t 3 j$ & $T 3=(t 31+t 32+t 33+t 34) \times f$ \\
$d j$ & $D=[(d 1 \times e 1+d 2 \times e 2+d 3 \times e 3+d 4 \times e 4) / e] \times f$ \\
\hline
\end{tabular}

Fonte: elaborada pelos autores.

\section{Análise de dados}

A análise estatística dos dados relativos à utilização da PEA para as CNC2015 foi realizada com a utilização do software estatístico R (THE R PROJECT..., 2004). Primeiramente, foi feita a análise univariada através do cálculo de medidas estatísticas, cujo intuito foi obter uma descrição sumária dos dados. Em seguida, recorreu-se a técnicas estatísticas multivariadas para se investigar as relações entre as variáveis em estudo. Concretamente, foi executada uma análise fatorial com o objetivo de detetar padrões de correlações entre as variáveis agregadas e, consequentemente, identificar fatores latentes subjacentes às variáveis (JOHNSON; WICHERN, 2007). Para averiguar a adequabilidade do modelo fatorial aos dados, calculou-se a medida de Kaiser-Meyer-Olkin (KMO) e a medida de adequação MSA para cada variável. Para identificar o número de fatores a serem retidos no modelo fatorial, foi tido em conta, primeiramente, o critério de Kaiser, que sugere tomar todos os fatores com variância superior a 1, e, seguidamente, a percentagem de variância total explicada pelos fatores retidos. Embora não exista um valor limiar para essa percentagem, universalmente aceite para todas as ciências ou aplicações (HAIR JR. et al., 2010), optou-se por garantir um nível satisfatório que permitisse obter ainda um modelo parcimonioso tanto quanto possível e, simultaneamente, com fatores interpretáveis. $\mathrm{Na}$ extração dos fatores utilizou-se o método das componentes principais; após terem sido analisadas várias rotações, optou-se pela rotação varimax, pois esta permitiu uma melhor identificação dos fatores retidos. Na identificação dos fatores latentes foram consideradas as cargas fatoriais com maior contribuição de explicação, tendo sido tomados os coeficientes que apresentaram magnitude absoluta superior ou igual a 0.5. Essas cargas fatoriais, que também são chamadas de loadings, assumem valores no intervalo $(-1,1)$ e representam as correlações entre os fatores e as variáveis. Foi ainda calculada a comunalidade de cada variável, que representa o percentual de variância da variável que é reproduzida pelos fatores do modelo fatorial (HENSON; CAPRARO; CAPRARO, 2001). Identificados os fatores latentes, foram estimadas as suas pontuações padronizadas (i.e., com média nula e desvio padrão unitário no conjunto das 143 
escolas) para cada escola. Com vista a analisar a existência de tipologias de escolas com base na diversidade de combinações de áreas (grupos disciplinares) participantes nas CNC, estatísticas descritivas (médias e desvios padrão) foram calculadas sobre as pontuações estimadas de cada fator em subgrupos de escolas que participaram num mesmo número de competições. Assim, subgrupos de escolas com pontuações médias positivas (negativas) num fator revelarão grupos disciplinares de escolas com comportamento nesse fator superior (inferior) à média de todas as 143 escolas; e, subgrupos de escolas com valores de desvio padrão num fator relativamente afastados do valor unitário, por falta ou por excesso, revelarão subgrupos de escolas com uma menor ou maior, respetivamente, dispersão do fator face ao padrão das 143 escolas.

\section{Resultados e discussão}

Na Tabela 3 encontram-se calculadas estatísticas descritivas para as doze variáveis originais descritas no Quadro 1 e as variáveis agregadas descritas na Tabela 2. Entre as quatro competições, destacam-se em negrito, por variável, a média mais elevada e, em itálico, o maior valor do coeficiente de variação (indicando, consequentemente, a maior percentagem de variabilidade quando comparada ao valor da média). Analisando, na Tabela 3, as quantidades relativas aos períodos de uma e três semanas que antecedem as CNC2015 entre as quatro competições $(a 1 j, r 1 j, t 1 j, a 3 j, r 3 j, t 3 j$ para $j=1,2,3,4)$, verifica-se que é em relação às competições EQUAmat e Dar@língua que se registra, em termos médios, a maior atividade desenvolvida na PEA, com maior número médio de treinos e maior número médio de alunos a acederem à plataforma na semana anterior às competições. Comparando os valores do coeficiente de variação dessas caraterísticas, conclui-se que a competição FisQ é a competição que exibe percentagens de variabilidade, relativamente às correspondentes médias, mais elevadas quanto ao número de acessos diários e no tempo de treinos pelas escolas, uma e três semanas antes das CNC2015, enquanto que a competição Dar@língua exibe maior variabilidade no número de treinos; a EQUAmat apresenta a menor variabilidade no número de acessos e no tempo de treino uma semana antes do evento.

Em termos de desempenho nas CNC2015, é na Geo@net que as escolas obtiveram, em termos médios, a sua pior participação, atingindo apenas 4\% do valor da pontuação máxima possível dessa competição (média de $d 3=0.04$ ); nas restantes três competições, as escolas tenderam a atingir cerca de $1 / 4$ da pontuação máxima possível da correspondente competição (média de $d 1=0.28$, média de $d 2=0.25$, média de $d 4=0.26$ ), tendo sido a competição Dar@ língua a que exibe maior número médio de equipas por competição. O coeficiente de variação do desempenho das escolas é mais elevado na competição Geo@net, com desvio padrão superior ao valor da média em $10 \%(\mathrm{CV}$ de $d 3=1.10)$. Confrontando os dados relativos à atividade da escola três semanas $(a 3 j, r 3 j, t 3 j)$ e uma semana $(a 1 j, r 1 j, t 1 j)$ antes das competições oficiais, em termos médios por competição, registram-se maiores tempos e número de acessos aos treinos na semana anterior ao evento (médias de $a 1 j, r 1 j$ e $t 1 j>$ médias de $a 3 j, r 3 j$ e $t 3 j$, resp., para $j=1$, $2,3,4)$ em todas as competições; porém, na EQUAmat, há uma dinâmica de atividade menos diferenciada entre as escolas (em termos médios) na semana que antecede à competição (CV de $a 11, r 11, t 11<\mathrm{CV}$ de $a 31, r 31, t 31$, resp., e CV de $a 1 j, r 1 j, t 1 j>\mathrm{CV}$ de $a 3 j, r 3 j, t 3 j$, resp., $\operatorname{com} j=2,3,4)$. 
Tabela 3. Média (M) e coeficiente de variação (CV) das variáveis originais (para as quatro competições) e das variáveis agregadas

\begin{tabular}{|c|c|c|c|c|c|c|c|c|c|c|c|}
\hline \multirow{2}{*}{$\begin{array}{l}\text { Variável } \\
\text { Original }\end{array}$} & \multicolumn{2}{|c|}{$\begin{array}{c}\text { EQUAmat } \\
(\mathrm{n}=140)\end{array}$} & \multicolumn{2}{|c|}{$\begin{array}{c}\text { Dar@língua } \\
(\mathrm{n}=28)\end{array}$} & \multicolumn{2}{|c|}{$\begin{array}{c}\text { Geo@NET } \\
(\mathrm{n}=21)\end{array}$} & \multicolumn{2}{|c|}{$\begin{array}{c}\text { FisQ } \\
(n=22)\end{array}$} & \multirow{2}{*}{$\begin{array}{l}\text { Variável } \\
\text { Agregada }\end{array}$} & \multicolumn{2}{|c|}{$\begin{array}{c}\text { CNC } \\
(n=143)\end{array}$} \\
\hline & $\mathbf{M}$ & $\mathrm{CV}$ & $\mathbf{M}$ & $\mathrm{CV}$ & $\mathbf{M}$ & $\mathrm{CV}$ & $\mathbf{M}$ & $\mathrm{CV}$ & & $\mathbf{M}$ & $\mathrm{CV}$ \\
\hline$a$ & --- & --- & --- & --- & --- & --- & --- & --- & $A$ & 129.9 & 1.04 \\
\hline$p$ & --- & --- & --- & --- & --- & --- & --- & --- & $P$ & 3.8 & 1.22 \\
\hline$e j$ & 10.8 & 0.44 & 11.2 & 0.44 & 9.0 & 0.62 & 6.7 & 0.83 & $E$ & 15.2 & 1.35 \\
\hline$u 1$ & --- & --- & --- & --- & --- & --- & --- & --- & U1 & 130.2 & 0.98 \\
\hline u3 & --- & --- & --- & --- & --- & --- & --- & --- & U3 & 89.8 & 0.73 \\
\hline a1j & 9.9 & 0.74 & 10.0 & 0.95 & 6.3 & 0.85 & 5.3 & 1.47 & $A 1$ & 6.6 & 0.61 \\
\hline$r 1 j$ & 126.8 & 1.39 & 204.6 & 2.05 & 75.8 & 1.03 & 33.7 & 1.76 & R1 & 82.5 & 0.45 \\
\hline$t 1 j$ & 376.8 & 0.75 & 207.2 & 0.93 & 139.4 & 1.12 & 208.6 & 1.15 & T1 & 195.2 & 0.90 \\
\hline$a^{3} j$ & 7.0 & 1.39 & 4.7 & 1.27 & 2.8 & 1.59 & 1.68 & 1.64 & $A 3$ & 3.9 & 0.49 \\
\hline$r 3 j$ & 66.8 & 1.78 & 46.2 & 2.16 & 24.7 & 1.66 & 7.0 & 1.93 & R3 & 35.3 & 0.45 \\
\hline$t 3 j$ & 220.0 & 1.03 & 64.1 & 1.43 & 47.7 & 1.51 & 63.1 & 1.49 & T3 & 99.8 & 0.75 \\
\hline$d j$ & 0.28 & 0.64 & 0.25 & 0.68 & 0.04 & 1.10 & 0.26 & 0.75 & $D$ & 0.10 & 1.12 \\
\hline
\end{tabular}

Fonte: elaborada pelos autores.

Considerando as variáveis agregadas, ou seja, do ponto de vista aglomerado da participação das escolas nas CNC, destaca-se, em média, uma maior atividade das escolas a uma semana do evento (médias de $A 1, \mathrm{R} 1$ e $\mathrm{T} 1>$ médias de $A 3, \mathrm{R} 3$ e $\mathrm{T} 3$, resp.), com tendência para uma dinâmica de trabalho mais diferenciada entre escolas na semana anterior ao evento do que três semanas antes (CV de $A 1, \mathrm{R} 1$ e $T 1>\mathrm{CV}$ de $A 3$, $\mathrm{R} 3$ e $T 3$, resp.). Continuando o foco do estudo numa perspetiva global das CNC, a adequação de um modelo fatorial, tomando os dados empíricos relativos às 12 variáveis agregadas, revelou-se bastante razoável, com o nível de variância comum dos dados com KMO $=0.791$ e valores de MSA para as doze variáveis agregadas entre 0.663 e 0.933 . O critério de Kaiser sugere a retenção de dois fatores no modelo com uma percentagem de variabilidade explicada de $66.1 \%$ e uma comunalidade a variar entre 0.42 e 0.81 (dados não mostrados). A fim de aumentar a percentagem de variabilidade total explicada e aprimorar a interpretação dos fatores no modelo fatorial, optou-se por considerar um modelo com quatro fatores resultando numa percentagem de variância total explicada de $81.3 \%$. A Tabela 4 mostra a percentagem de variância explicada e as cargas fatoriais de cada um dos quatro fatores retidos no modelo fatorial após a rotação varimax, destacando-se, em negrito, as cargas com maior influência na identificação dos fatores latentes F1, F2, F3 e F4. Os quatro fatores retidos conseguem captar grande parte da variabilidade de quase todas as variáveis agregadas com comunalidades superiores a 0.68 . 
Silva, A. O.; Freitas, A.; Oliveira, M. P. S.; Silva, A. M.

Tabela 4. Cargas dos fatores, percentagem de variabilidade de cada fator e comunalidades

\begin{tabular}{cccccc}
\hline Variável & $\mathbf{F 1}$ & $\mathbf{F 2}$ & $\mathbf{F 3}$ & $\mathbf{F 4}$ & Comunalidade \\
A3 & $\mathbf{0 . 8 8 3}$ & 0.170 & 0.302 & 0.067 & 0.905 \\
R3 & $\mathbf{0 . 8 3 0}$ & 0.380 & 0.113 & 0.167 & 0.873 \\
A1 & $\mathbf{0 . 6 8 4}$ & 0.303 & $\mathbf{0 . 5 2 0}$ & 0.143 & 0.851 \\
R1 & $\mathbf{0 . 6 1 5}$ & $\mathbf{0 . 6 2 6}$ & 0.102 & 0.094 & 0.790 \\
U1 & 0.247 & $\mathbf{0 . 8 6 0}$ & 0.142 & 0.044 & 0.823 \\
T1 & 0.332 & $\mathbf{0 . 7 6 9}$ & 0.330 & 0.126 & 0.826 \\
T3 & 0.356 & $\mathbf{0 . 5 9 0}$ & 0.356 & 0.280 & 0.680 \\
U3 & 0.031 & $\mathbf{0 . 5 1 7}$ & $\mathbf{0 . 6 3 9}$ & 0.061 & 0.680 \\
E & 0.308 & 0.093 & $\mathbf{0 . 8 7 0}$ & 0.153 & 0.883 \\
D & 0.379 & 0.396 & $\mathbf{0 . 6 4 6}$ & 0.269 & 0.789 \\
P & 0.075 & 0.247 & 0.043 & $\mathbf{0 . 8 7 4}$ & 0.833 \\
A & 0.134 & -0.042 & 0.220 & $\mathbf{0 . 8 6 8}$ & 0.822 \\
Variância $(\%)$ & $24.0 \%$ & $23.6 \%$ & $18.9 \%$ & $14.8 \%$ & \\
\hline
\end{tabular}

Fonte: elaborada pelos autores.

As correlações entre as variáveis originais e os fatores, dadas pelas cargas fatoriais (Tabela 4), permitem-nos distinguir os seguintes fatores latentes:

- F1, que designamos por Treino quantitativo: está altamente correlacionado com as variáveis $A 3$ e $\mathrm{R} 3$ e, mais moderadamente, com as variáveis $A 1$ e $\mathrm{R} 1$, representando a atividade preparatória experimental de treino (em termos quantitativos de número de treinos e de acessos à PEA, três e uma semana antes das competições) desenvolvida por parte dos alunos. Deduz-se que corresponda ao trabalho de preparação para as $\mathrm{CNC}$ com a PEA;

- F2, que designamos por Treino qualitativo: está mais associado às variáveis $U 1, T 1$, R1, T3 e U3. Deduz-se que corresponda ao trabalho mais incisivo realizado para alcançar um melhor resultado nas competições. O tempo despendido em consulta à plataforma (U1 e U3), o tempo médio de treino (T1 e T3) e o número de treinos uma semana antes das CNC (R1) relacionam-se na medida em que o desempenho dos alunos nos treinos é analisado por professores e alunos, detetando as falhas cometidas e tentando corrigi-las com vista a um melhor desempenho nas competições. Podemos conjeturar que este fator contém a tarefa de realização de exercícios que podem conduzir, por exemplo, à seleção dos "melhores" alunos e equipes a participar na competição, bem como definir estratégias para alcançar melhores resultados;

- F3, que designamos por Prestação: está associado às variáveis $E, D, U 3$ e $A 1$, refletindo a contribuição da escola para alcançar sucesso nas competições oficiais. Pode retratar os preparativos com a exploração da PEA (U3), a seleção de alunos para as equipes que irão representar a escola nas competições oficiais $(E$ e $A 1)$ e o resultado final atingido na competição $(D)$;

- $\mathbf{F} 4$, que designamos por Utilizadores: está associado às variáveis $P$ e $A$, correspondendo aos utilizadores da PEA, professores e alunos, os principais beneficiários da plataforma.

Nestas circunstâncias, podemos conjeturar que os fatores Treino quantitativo e Treino qualitativo fornecem informação sobre o empenho da escola na sua preparação para as CNC, evidenciando a utilização da PEA para as competições oficiais. O fator Prestação sintetiza o resultado da estratégia de atuação da escola nas competições, enquanto o fator Utilizadores reflete 
a estrutura humana de base, definida pelos recursos (alunos e professores) que recorrem à PEA. A Tabela 5 exibe a média e o desvio padrão dos valores estimados para cada um desses quatro fatores, após padronização, por subgrupos de escolas que participaram num mesmo conjunto de competições nas CNC. Destacam-se, em negrito, as médias mais elevadas por fator e, em itálico, os valores de desvio padrão mais elevados e mais baixos.

Tabela 5. Média e desvio padrão dos valores estimados de cada um dos quatros fatores, por combinações de grupos disciplinares

\begin{tabular}{|c|c|c|c|c|c|c|c|c|c|}
\hline \multirow{2}{*}{$\begin{array}{c}\text { Grupos } \\
\text { disciplinares }\end{array}$} & \multirow{2}{*}{$\begin{array}{l}\text { Escolas } \\
(n=143)\end{array}$} & \multicolumn{2}{|c|}{$\begin{array}{c}\text { Treino } \\
\text { quantitativo }\end{array}$} & \multicolumn{2}{|c|}{$\begin{array}{c}\text { Treino } \\
\text { qualitativo }\end{array}$} & \multicolumn{2}{|c|}{ Prestação } & \multicolumn{2}{|c|}{ Utilizadores } \\
\hline & & $\mathbf{M}$ & DP & $\mathbf{M}$ & DP & $\mathbf{M}$ & DP & $\mathbf{M}$ & DP \\
\hline $\mathrm{M}$ & 98 & -0.15 & 0.31 & -0.27 & 0.66 & -0.37 & 0.39 & -0.03 & 0.98 \\
\hline $\mathrm{L}$ & 1 & -0.20 & --- & -0.12 & --- & -0.06 & $\begin{array}{ll}-- \\
\end{array}$ & -0.75 & --- \\
\hline G & 1 & -0.29 & --- & 0.62 & --- & -0.84 & --- & -0.53 & --- \\
\hline $\mathrm{F}$ & 1 & -0.39 & --- & 0.09 & --- & -0.88 & --- & 0.10 & --- \\
\hline ML & 12 & 0.59 & 1.60 & 0.62 & 1.53 & 0.37 & 1.06 & -0.25 & 0.48 \\
\hline MG & 7 & -0.05 & 0.76 & 0.50 & 0.95 & 0.24 & 0.79 & -0.08 & 0.60 \\
\hline MF & 3 & 1.14 & 2.01 & 0.91 & 1.81 & 0.37 & 0.82 & -0.07 & 0.65 \\
\hline MLG & 2 & -0.41 & 0.18 & 1.26 & 1.61 & 0.08 & 0.04 & 1.46 & 3.03 \\
\hline MLF & 7 & 0.38 & 1.31 & -0.15 & 1.07 & 1.11 & 1.14 & 0.67 & 1.45 \\
\hline MGF & 5 & -0.67 & 1.29 & 1.54 & 1.14 & 1.44 & 1.73 & 0.18 & 1.38 \\
\hline MLGF & 6 & 1.11 & 3.30 & 0.44 & 1.74 & 2.63 & 1.56 & -0.08 & 0.93 \\
\hline
\end{tabular}

Fonte: elaborada pelos autores.

Da Tabela 5 constata-se que, entre os subgrupos de escolas que participaram em mais uma competição para além da EQUAmat (subgrupos ML, MG e MF), a tendência média é para se registrar maior dinamismo nas escolas onde a segunda competição tenha sido Dar@língua ou FisQ. Na realidade, nos subgrupos de escolas ML e MF, registra-se maior empenho médio nas atividades dos treinos, quer por apresentarem maior quantidade média de treinos (médias de 0.59 e 1.14 no fator Treino quantitativo), quer por exibirem em média maior dedicação à análise dos treinos (média de 0.62 e 0.91 no fator Treino qualitativo), produzindo, em média, uma prestação nas CNC mais positiva (média de 0.37 no fator Prestação). Entre os subgrupos de escolas que participaram em duas competições para além do EQUAmat (subgrupos MLG, MLF e MGF), os resultados da Tabela 5 mostram que as escolas que participaram em Geo@, NET (subgrupos MLG e MGF) têm menor número médio de alunos a aceder a PEA e menor número de treinos (média de -0.41 e -0.67 no fator Treino quantitativo), mas mais tempo de acesso à PEA, quer para consulta quer para treino (média de 1.26 e 1.54 no fator Treino qualitativo), contrariamente às escolas que participaram em Dar@língua e FisQ (i.e., o subgrupo MLF) (média de 0.38 no fator Treino quantitativo e -0.15 no fator Treino qualitativo). Das escolas que participaram em uma ou duas competições para além da EQUAmat, mas com participação em FisQ, espera-se uma melhor prestação nas CNC (média de 0.37 para o subgrupo MF, 1.11 para o subgrupo MLF e 1.44 para o subgrupo MGF). Ainda da Tabela 5, relativamente às seis escolas que participaram nas quatro competições (subgrupo MLGF), embora o modelo 
fatorial acuse que, em média, tais escolas realizaram uma maior atividade preparatória de treino (média de 1.11 no fator Treino quantitativo), os (poucos) dados sugerem que a sua atuação é diferenciada (desvio padrão de 3.30 no fator Treino quantitativo). Para além disso, e como esperado, tais escolas apresentam a melhor prestação na perspetiva global das CNC, uma vez que participaram nas quatro competições. Em termos de utilizadores da PEA (alunos e professores), as duas escolas que participaram nas competições EQUAmat, Dar@língua e Geo@ NET (subgrupo MLG) exibem o maior valor médio, mas com grande variabilidade (média de 1.46 e desvio padrão de 3.03 no fator Utilizadores); contudo, este fato não é impactante, já que este subgrupo é constituído por apenas duas escolas.

\section{Conclusões}

A participação nas $\mathrm{CNC}$, inserida nas atividades pedagógicas de escola, potencializa nos alunos a cooperação (jogos de equipes), pensamento crítico e a motivação. Na realidade, tomando a vertente competição, como vários autores referem, ao motivar extrinsecamente os alunos, a competição permite promover um maior envolvimento nas tarefas curriculares (VAN ECK; DEMPSEY, 2002), estimulando o interesse dos estudantes e aumentando a eficácia do processo de aprendizagem (ATANASIJEVIC-KUNC et al., 2011). Contudo, na sequência das ideias expressas por Miranda (2007), é preciso definir regras e objetivos que perfilem com conteúdos curriculares, com vista a colher o melhor impacto no rendimento escolar dos alunos. Saliente-se também que, nas $\mathrm{CNC}$, os alunos têm como oponentes outros alunos em vez de um jogador virtual, o que, de acordo com Cagiltay, Ozcelik e Ozcelik (2015), pode ser um fator que afeta a motivação e melhora o desempenho, bem como fomenta a aprendizagem. De fato, quando os participantes jogam contra um oponente humano, experimentam um maior entusiasmo do que os que enfrentam um oponente virtual (WILLIAMS; CLIPPINGER, 2002). As competições $\mathrm{CNC}$, que recorrem às tecnologias da informação, enquadram-se nesta linha de ação, com jogos versando sobre conteúdos curriculares para promoção de aprendizagens efetivas.

$\mathrm{Na}$ linha de pensamento de Vygotsky (1991), espera-se que o envolvimento dos alunos nas atividades desenvolvidas nas escolas no âmbito das CNC, e o próprio evento em si, propicie avanço no desenvolvimento potencial dos alunos. Da análise dos dados realizada destaca-se, em primeiro lugar, a elevada participação das escolas apenas na competição EQUAMat (98 das 143), o que se pode justificar pelo histórico de mais de 20 anos dessa competição, em oposição aos menos de 7 anos de existência das outras competições. Além de ser a que envolve mais estudantes, é ainda a responsável pela maior contribuição no empenho global da escola nas CNC. $\mathrm{Na}$ realidade, a EQUAMat é a competição de excelência do projeto, indo de encontro ao fato de a Matemática ser a disciplina dos jogos. Quando se analisam as atividades desenvolvidas pelos quatro grupos disciplinares (Matemática, Português, Geologia e Físico-Química) em períodos que antecedem as competições oficiais, é o grupo de Matemática que exibe uma tendência para uma dinâmica de trabalho em geral mais forte, fato que se pode novamente justificar pela longevidade da competição. Nos dados analisados, constata-se que este grupo apresenta uma linha de atuação mais concertada ou programada (i.e., menos diferenciada entre escolas, em particular, com o número de alunos que treinam e o tempo médio desse treino a uma semana antes do evento oficial). Dada a dimensão elevada de participação das escolas apenas na 
competição EQUAmat, para investigação futura será importante analisar com maior detalhe a dinâmica de trabalho implementada pelas escolas na sua preparação para esta competição em particular, até porque muitas das estratégias de atuação já devem estar definidas de ano para ano, dada a tradição e participação que uma eventual escola tenha no seu histórico, e como os dados demonstraram, existe uma maior estabilização de atuação/dinâmica preparatória das escolas nesta competição.

Quando levado em consideração o número de competições em que as escolas participaram nas CNC, observa-se uma tendência para as escolas envolvidas em duas ou três competições (42 das 143) que incluam Matemática e Físico-Química, disciplinas muito próximas em termos de abordagem curricular, exibirem melhores desempenhos durante as competições oficiais, embora tais grupos de escolas demonstrem diferentes dinâmicas de trabalho de preparação. Contudo, o número reduzido de escolas que fazem parte de cada uma das diferentes combinações de grupos disciplinares não permite conjeturar um padrão de comportamento face a essa dinâmica. Por outro lado, o fato das escolas alcançarem, em média, apenas cerca de $1 / 4$ da pontuação máxima em competições associadas a três grupos disciplinares e apenas 4\% da pontuação máxima no quarto grupo deve ser objeto de maior estudo. Concretamente, interessará correlacionar o desempenho das escolas nas CNC com o desempenho médio escolar dos alunos envolvidos, assim como avaliar as implicações pedagógicas do envolvimento das escolas nessas competições. Estes tópicos requerem a realização e análise de inquéritos que estão fora do âmbito do presente estudo.

\section{Agradecimentos}

Trabalho subsidiado por fundos portugueses através do Centro de Investigação e Desenvolvimento em Matemática e Aplicações (CIDMA) da Universidade de Aveiro, e da Fundação para a Ciência e a Tecnologia (FCT), dentro do projeto UID/MAT/04106/2013.

\section{Referências}

ANJO, A. B.; OLIVEIRA, P. PmatE: an old project in education, teaching and learning using new technologies. In: INTERNATIONAL CONFERENCE OF EDUCATION, RESEARCH AND INNOVATION, ICERI2010, 2010, Madrid. Proceedings... Madrid: IATED, 2010, p. 7249-7253.

ATANASIJEVIC-KUNC, M. et al. Remote multivariable control design using a competition game. IEEE Transactions on Education, Columbus, v. 54, n. 1, p. 97-103, 2011.

BLACK, P.; ATKIN, J. M. Changing the subject, innovations in science, mathematics and technology education. London: OECD: Routledge, 1996.

CAGILTAY, N. E.; OZCELIK, E.; OZCELIK N. S. The effect of competition on learning in games. Computers \& Education, New York, v. 87, p. 35-41, 2015.

CHENG, H. N. et al. Equal opportunity tactic: redesigning and applying competition games in classrooms. Computers \& Education, New York, v. 53, n. 3, p. 866-876, 2009. 
Silva, A. O.; Freitas, A.; Oliveira, M. P. S.; Silva, A. M.

COHEN, L.; MANION, L.; MORRISON, K. Research methods in education. 5. ed. London: Routledge: Falmer, 2000.

COUTINHO, C. P.; LISBÔA, E. Sociedade da informação, do conhecimento e da aprendizagem: desafios para a educação no século XXI. Revista de Educação, Lisboa, v. 18, n. 1, p. 5-22, 2011.

FOUREZ, G. Crise no ensino de ciências? Investigações em Ensino de Ciências, Porto Alegre, v. 8, n. 2, p. 109-123, 2003.

HAIR JR., J. F. et al. Multivariate data analysis. 7. ed. Upper Saddle River: Pearson Education, 2010.

HENSON, R. K.; CAPRARO, R. M.; CAPRARO, M. M. Reporting practice and use of exploratory factor analysis in educational research journals. In: ANNUAL MEETING OF THE MID-SOUTH EDUCATIONAL RESEARCH ASSOCIATION, 2001, Little Rock, AR. Proceedings... Disponível em: < https:/ files.eric.ed.gov/fulltext/ED466780.pdf>. Acesso em: 17 ago. 2018.

HILL, M. M.; HILL, A. Investigação por questionário. 2. ed. Lisboa: Sílabo, 2008.

JOHNSON, R. A.; WICHERN, D. W. Applied multivariate statistical analysis. 6. ed. Upper Saddle River: Pearson Prentice Hall, 2007.

MIRANDA, G. L. Limites e possibilidades das TIC na educação. Sísifo: revista de ciências da educação, Lisboa, n. 3, p. 41-50, 2007.

NEGRINE, A. Aprendizagem e desenvolvimento infantil: psicomotricidade alternativas pedagógicas. Porto Alegre: Prodil, 1995. v. 3.

OLIVEIRA, M. K. Vygotsky: aprendizado e desenvolvimento: um processo socio-histórico. São Paulo: Scipione, 2010.

PAIS, S.; CABRITA, I.; ANJO, A. B. A plataforma PmatE e o desenvolvimento de apetências em matemática. Indagatio Didactica, Aveiro, p. 219-241, v. 6, n. 1, 2014.

PEIXOTO, E. et al. Geo@NET in the context of the platform of assisted learning from Aveiro University. In: CRUZ-CUNHA, M. M. (Ed.). Handbook of research on serious games as educational, business and research tools. Hershey: Information Science Reference, 2012. v. 1. p. 648-667.

THE R PROJECT for statistical computing. [2004]. Disponível em: <https://www.r-project. org/>. Acesso em: 16 ago. 2018.

REGO, T. C. Vygotsky: uma perspectiva histórico-cultural da educação. 10. ed. Petrópolis: Vozes, 2000.

REZENDE, F. As novas tecnologias na prática pedagógica sob a perspectiva construtivista. Ensaio: pesquisa em educação em ciências, Belo Horizonte, v. 2, n. 1, p. 70-87, 2002.

SAMPAIO, P. A. S. R.; COUTINHO, C. P. Ensinar matemática com TIC: em busca de um referencial teórico. Revista Portuguesa de Pedagogia, Coimbra, v. 46-2, p. 91-108, 2012. 
SILVA, A. F.; KODAMA, H. M. Y. Jogos no ensino da matemática. In: BIENAL DA SOCIEDADE BRASILEIRA DE MATEMÁTICA, 2., 2004, Salvador. Anais... Disponível em: <http://www.bienasbm.ufba.br/OF11.pdf>. Acesso em: 13 maio 2016.

SIMÕES, J.; REDONDO, R. D.; FERNÁNDEZ, A. A social gamification framework for a K-6 learning platform. Computers in Human Behavior, Amsterdam, v. 29, n. 2 , p. 345-353, 2013.

VAN ECK, R.; DEMPSEY, J., The effect of competition and contextualized advisement on the transfer of mathematics skills in a computer-based instructional simulation game.

Educational Technology, Research and Development, New York, v. 50, n. 3, 23-41, 2002.

VYGOTSKY, L. S. A formação social da mente. São Paulo: Martins Fontes, 1991.

WILLIAMS, R. B.; CLIPPINGER, C. A. Aggression, competition and computer games: computer and human opponents. Computers in Human Behavior, Amsterdam, v. 18, n. 5, p. 495-506, 2002.

WORRELL, F. C. et al. Competition's role in developing psychological strength and outstanding performance. Review of General Psychology, Washington, v. 20, n. 3, p. 259-271, 2016.

Artigo recebido em 08/08/2017. Aceito em 23/12/2017. 
